\title{
Photoelastic Studies of Some Polybutadiene Networks
}

\author{
James E. MARK and Miguel A. LlORENTE* \\ Department of Chemistry and the Polymer Research Center, \\ The University of Cincinnati, Cincinnati, Ohio 45221, U.S.A.
}

(Received September 13, 1980)

\begin{abstract}
Two butadiene polymers were used in this investigation, one with $98.5 \%$ cis-1,4 units and the other with an approximately equibinary mixture of cis and trans units. Elastomeric networks prepared from these polymers were studied in elongation, in both the swollen and unswollen states over the temperature range -30 to $95^{\circ} \mathrm{C}$. There is evidence for crystallization in these networks, particularly as manifested by marked increases in birefringence at relatively low elongations and at temperatures as high as $40^{\circ} \mathrm{C}$. As expected, the birefringence and related quantities were found to be more sensitive to crystallization than the force, with the opticalconfiguration parameter and the stress-optical coefficient showing the greatest sensitivity. In the case of the cis-trans copolymer, the crystallization involves trans sequences, which are of relatively high melting point, and thus occurs at a temperature higher than for the lower melting cis sequences in the high-cis networks. The results which were free from the effects of network crystallization were used to calculate values of the temperature coefficient of the unperturbed dimensions of the chains, and values of the optical-configuration parameter. These configuration-dependent properties were found to be in satisfactory agreement with previously published theoretical results based on a rotational isomeric state model of these chain molecules.
\end{abstract}

KEY WORDS Radiation Cross-Linking / Thermoelasticity / Network Crystallization / Unperturbed Dimensions / Rotational Isomeric State Theory / Photoelasticity / Strain-Birefringence / Optical-Configuration Parameter / Stress-Optical Coefficient /

One of the most important classes of elastomeric materials is that prepared from the polybutadienes. ${ }^{1}$ A wide variety of elastomers of this type are available because of the nature of the repeat unit, which can adopt either the cis-1,4, trans-1,4 or vinyl-1,2 forms depending on the catalyst used to prepare the polymer. ${ }^{2,3}$ This variability can obviously have a profound effect on the crystallizability of these networks and is therefore of great importance with regard to their mechanical properties. It is also of interest to theorists ${ }^{4-6}$ seeking to understand the effect of structure on statistical properties through rotational isomeric state calculations. ${ }^{\text {? }}$

One question of importance which is particularly relevant to the mechanical properties of butadiene elastomers is the amount of crystallization occurring

* Postdoctoral Fellow under the Joint Spain-United States Treaty for Scientific and Technological Cooperation. in the networks (in both the stretched and unstretched states). This crystallization could involve both sequences of $c i s$ units (having a melting point of $t_{\mathrm{m}}{ }^{\circ}$ of $\left.0^{\circ} \mathrm{C}\right)^{8-10}$ and trans units (which can crystallize in two modifications, having $t_{\mathrm{m}}{ }^{\circ}=100$ and $146^{\circ} \mathrm{C}$, respectively) ${ }^{8-10}$ The (maximum) melting point $t_{\mathrm{m}}$ of a butadiene cis-trans copolymer can therefore be calculated from the appropriate values of $t_{\mathrm{m}}{ }^{\circ}$ and the heats of fusion of the pure comonomers, ${ }^{8-11}$ through use of the standard Flory theory ${ }^{9,12}$ of the melting point depression. The basic equation (for either cis or trans sequences) is

$$
1 / T_{\mathrm{m}}-1 / T_{\mathrm{m}}{ }^{\circ}=-\left(R / \Delta H_{\mathrm{u}}\right) \ln p
$$

where $T$ 's are absolute temperatures, $R$ is the gas constant, $\Delta H_{\mathrm{u}}$ is the heat of fusion per mol of repeat units, and $p$ is the probability for their replication along the chains. In the case of a perfectly random cis-trans copolymer, $p$ would be equal to the mol 


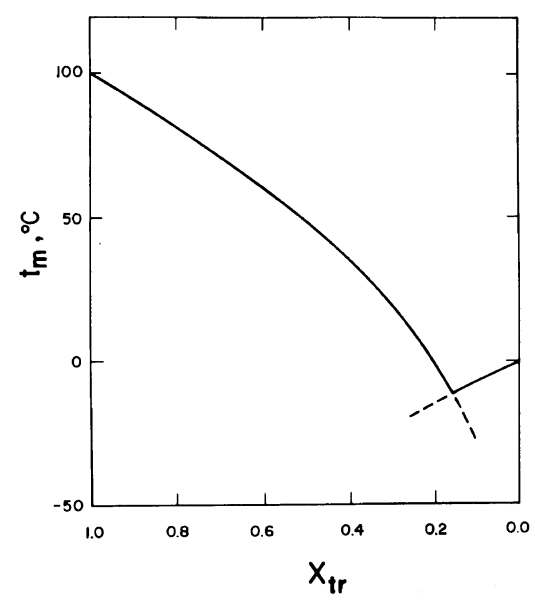

Figure 1. The dependence of the (maximum) melting point of random-sequence cis-trans butadiene copolymers on the fraction of trans units, as calculated from the standard theory ${ }^{12}$ of melting point depression. Except for the small region $X_{t r}<0.15$, the maximum $t_{\mathrm{m}}$ is that of the trans rather than cis sequences.

(or wt) fraction $X_{\mathrm{i}}$ of units of the specified type. The results of typical calculations are shown in Figure 1, where $X_{t r}$ is the mole fraction of trans units. (The values of $T_{\mathrm{m}}{ }^{\circ}$ and $\Delta H_{\mathrm{u}}$ chosen for these units are for the lower-melting modification. ${ }^{8-10}$ Similar calculations for the higher-melting modification indicate that because of its lower $\Delta H_{\mathrm{u}}$, its melting point in these copolymers remains higher only for relatively high trans contents $\left(X_{t r}>0.72\right)$. This composition range is of no relevance in the present investigation).

The line to the left in the Figure represents the melting point depression curve for the trans units, and that to the right the one for the cis units. Thus, except for very high cis content, the maximum melting point of a cis-trans copolymer is that of the trans sequences.

The above considerations are relevant to a recent experimental study on butadiene elastomers by Dossin and Graessley, ${ }^{13}$ in which elongation moduli were used to estimate the effect of inter-chain entanglements. It was there assumed that network crystallization was totally absent at $25^{\circ} \mathrm{C}$, in spite of the fact that the extraordinarily long periods of time required ${ }^{13}$ to reach elastic equilibrium strongly suggest $^{14}$ network crystallization, with annealing occurring during these extended periods of time. ${ }^{15}$ This is a serious assumption in view of the large effect even small crystallites could have by increasing the effective degree of crosslinking in the network. The butadiene elastomers investigated had average values of $X_{t r}$ of $0.38,0.45$, and 0.51 ; the remaining units were $c i s(0.55,0.47,0.40)$ and vinyl $(0.07,0.08,0.09){ }^{13}$ According to Figure 1, these compositions would give melting points of approximately 30,40 , and $50^{\circ} \mathrm{C}$, respectively. In addition, there could be a tendency for trans-sequence replication in butadiene copolymers $\left(p>X_{t r}\right)$, and even if there isn't, there is of course a range in values of the trans sequence lengths in any butadiene copolymer. Thus, thermodynamics, ${ }^{12}$ as embodied in the results shown in Figure 1, clearly indicates that a butadiene cis-trans copolymer having an average composition corresponding to $X_{t r}=0.5$ could have some crystallites persisting up to temperatures well above $60^{\circ} \mathrm{C}$. As is well known, stretching of such a network would cause significant increases in $T_{\mathrm{m}} \cdot{ }^{9,16,17}$

The present investigation addresses several of these issues. Specifically, two butadiene elastomers having $X_{\text {cis }}=0.985$ and 0.430 are studied in elongation, in both the swollen and unswollen states, over the temperature range -30 to $95^{\circ} \mathrm{C}$. The experiments involve measurements of both the elastic force and birefringence (which is extremely sensitive to crystallization) ${ }^{18-22}$ primarily under the condition of constant length. The results are scrutinized for evidence of network crystallization, and how it depends on chemical composition, degree of crosslinking, temperature, elongation, and presence of a swelling agent. (Such crystallization was readily detected by such measurements on several ethylene-propylene chemical copolymers. ${ }^{23}$ It should be considerably less pronounced in the present case judging from the differences in the melting points of the two systems, and differences in the discrepancy (probably from network crystallization) ${ }^{23}$ between theoretical $^{24,25}$ and observed ${ }^{13,26}$ values of the elongation modulus.) The data obtained under conditions where there is no evidence of cyrstallization are used to calculate values of the temperature coefficient of the unperturbed dimensions of the network chains, and values of the opticalconfiguration parameter. These values are then compared with the other experimental results and with the predictions of rotational isomeric state theory. 


\section{EXPERIMENTAL DETAILS}

\section{Materials}

The first butadiene polymer employed was generously provided by Professor S. Cesca of the Snamprogetti Laboratories (Milan, Italy). It was a high molecular weight sample which had been prepared with a special uranium catalyst ${ }^{27,28}$ so as to have an extremely high cis content of $98.5 \%{ }^{29}$ The second polymer was a commercial sample (SOLPRENE ${ }^{\circledR} 255$ polybutadiene) kindly contributed by Dr. G. Kraus of the Phillips Petroleum Company, and was prepared using a standard $n$ butyl lithium catalyst in the non-polar solvent cyclohexane. ${ }^{30}$ This polymer was a cis-trans copolymer having $47 \%$ trans, $43 \%$ cis, and $10 \%$ vinyl groups $^{30}$ and should be very nearly identical to the samples used in the previous investigation. ${ }^{13}$ Both samples were purified by precipitations into a non-solvent followed by extensive drying under vacuum. These samples were designated polymers $\mathrm{A}$ and $\mathrm{B}$, respectively.

The solvents chosen for the networks to be studied were reagent-grade 1,3,5-triethylbenzene and decalin, chosen for their relatively high boiling points $^{31}$ (low volatility). More than one solvent was chosen since it was known that different solvents can have different effects on the optical properties of a swollen network. ${ }^{21,32-37}$

This information is summarized in the first five columns of Table I.

\section{The Density and Index of Refraction}

The values of the density $\rho$ at $20^{\circ} \mathrm{C}$ for the two polymers and two solvents were obtained from the literature, ${ }^{31,38-40}$ and are given in column six of
Table I. Similarly obtained values ${ }^{39,41}$ of the cubical thermal expansion coefficient $\beta$ for the two (unswollen) polymers in the vicinity of $25^{\circ} \mathrm{C}$ are given in the following column.

The index of refraction of the high-cis polymer was taken from the literature, ${ }^{39}$ but had to be experimentally determined in the case of the cistrans copolymer. A thin film of the B sample was therefore obtained using a hydraulic laboratory press with plates heated to $100^{\circ} \mathrm{C}$. A precision Abbe refractometer was used to determine its values of the index of refraction $n_{\mathrm{D}}$ at the sodium $\mathrm{D}$ line, at the temperatures of interest in the present investigation. Similar measurements were carried out on the two solvents. All the results, expressed in terms of the constants $a$ and $b$ in the expression $n_{\mathrm{D}}=a-b t\left({ }^{\circ} \mathrm{C}\right)$, are given in the last two columns of Table I.

\section{Preparation of the Networks}

Portions of the two butadiene samples were pressed into aluminum molds at $100^{\circ} \mathrm{C}$, and the molds were then carefully sealed and irradiated at room temperature with $\gamma$ radiation from a ${ }^{60} \mathrm{Co}$ source. One network sheet (A1) was thus prepared from the first sample, using a dose of $21 \mathrm{Mrad}$, and two (B1-2) from the second, using doses of 12 and 21 Mrad, respectively. Each sheet was extracted in benzene for 1 week and then dried under vacuum. Strips having the appropriate dimensions $0.1 \times 0.5 \times 2.0 \mathrm{~cm}$ were cut from each of the sheets for the elasticity measurements.

\section{Apparatus}

The apparatus employed was standard for these types of force-birefringence measurements, and is described in detail in the literature. ${ }^{21,42}$ Briefly, the

Table I. Characteristics of butadiene polymers and swelling diluents

\begin{tabular}{|c|c|c|c|c|c|c|c|c|}
\hline \multirow{2}{*}{ Materials } & \multicolumn{3}{|c|}{$\%$ Composition } & \multirow{2}{*}{$\frac{T_{\mathrm{b}}^{\mathrm{a}}}{{ }^{\circ} \mathrm{C}}$} & \multirow{2}{*}{$\frac{\rho^{\mathrm{b}}}{\mathrm{g} \mathrm{cm^{-3 }}}$} & \multirow{2}{*}{$\frac{10^{3} \beta^{c}}{K^{-1}}$} & \multirow{2}{*}{$a^{\mathrm{d}}$} & \multirow{2}{*}{$10^{4} b^{\mathrm{d}}$} \\
\hline & cis & trans & Vinyl & & & & & \\
\hline Polymer $\mathrm{A}^{\mathrm{e}}$ & 98.5 & 1.5 & 0.0 & - & $0.960^{\mathrm{h}, \mathrm{i}}$ & $0.68^{\mathrm{i}}$ & $1.5341^{\mathrm{i}}$ & $3.560^{\mathrm{i}}$ \\
\hline Polymer $\mathrm{B}^{\mathrm{f}}$ & 43.0 & 47.0 & 10.0 & - & $0.896^{\mathrm{j}}$ & $0.75^{\mathrm{k}}$ & 1.5241 & 3.966 \\
\hline 1,3,5-Triethylbenzene & - & - & - & $216^{\mathrm{g}}$ & $0.863^{\mathrm{g}}$ & - & 1.5004 & 4.712 \\
\hline Decalin & - & - & - & $190^{\mathrm{g}}$ & $0.896^{\mathrm{g}}$ & - & 1.4832 & 4.714 \\
\hline
\end{tabular}

${ }^{a}$ Boiling point, at 1 atm pressure. ${ }^{b}$ Density, at $20^{\circ} \mathrm{C}$. ${ }^{c}$ Cubical thermal expansion coefficient. ${ }^{d}$ Constants for index of refraction $n_{\mathrm{D}}=a-b t$, with $t$ in ${ }^{\circ} \mathrm{C}$. ${ }^{\mathrm{e}}$ Snamprogetti laboratory sample. ${ }^{\mathrm{f}}$ Phillips SOLPRENE ${ }^{\circledR} 255 .{ }^{\mathrm{g}}$ Reference 31. ${ }^{\mathrm{h}}$ Reference 38. ${ }^{\mathrm{i}}$ Reference 39. ${ }^{\mathrm{j}}$ Reference $40 .{ }^{\mathrm{k}}$ Reference 41. 
light source was a $3 \mathrm{~mW} 632.8 \mathrm{~nm} \mathrm{He}-\mathrm{Ne}$ laser (Oriel Corporation), the polarizer and analyzer were Glan-Thompson prisms (Karl Lambrecht MGT 25E10), the compensator was the BabinetSoleil type (Karl Lambrecht BSO-13-1), the detector was a Photometer/Radiometer working with a silicon light probe (Karl Lambrecht 1030 and P1101S), and the optical bench and accessories were obtained from the Oriel Corporation. The glass sample cell had a double-wall jacket, thus permitting temperature control by circulation of a water-methanol solution through those parts of the cell not in the path of the laser beam. Temperatures were measured by a thermocouple located as close as possible to the sample strip. The elastic forces were measured using a Statham "strain" gauge, the signal of which was monitored by a Linear Corporation recorder.

\section{Mechanical and Optical Measurements}

The network strip being studied was mounted between two clamps within the cell, the lower one fixed and the upper one attached to the strain gauge. In the case of the unswollen samples, the strip was extended to the lowest desired value of the elongation $\alpha=L / L_{\mathrm{i}}$, at $40-50^{\circ} \mathrm{C}$. Typically, about two days were required to establish equilibrium at this temperature. The temperature was then increased to the highest value to be employed, generally $90^{\circ} \mathrm{C}$. Equilibrium was re-established after approximately $2 \mathrm{~h}$, and the values of the elastic force $f$ and birefringence $\Delta n$ were recorded. The temperature was then decreased, equilibrium re-established (after approximately $0.5 \mathrm{~h}$ ), and the new values of $f$ and $\Delta n$ recorded. After the lowest temperature desired was reached by this scheme, the temperature was increased in several steps to check the reversibility of the experiments. Although this type of regimen at constant length is considered the most reliable, ${ }^{36} \mathrm{a}$ few experiments were conducted by varying the length at constant temperature.

In the case of the swollen networks, it was more convenient to reverse the above basic procedure, by beginning the measurements at the lowest of the temperatures to be employed.

One strip of network B2 was studied using a Rheovibron Viscoelastometer in order to see if there were any viscoelastic losses which might be indicative of network crystallization. In the case of the swollen networks, the usual length-temperature measurements were used to obtain values of the thermal expansion coefficient $\beta$.

\section{RESULTS AND DISCUSSION}

All of the force-temperature ("thermoelastic") results were interpreted in terms of $\ln \left(f^{*} / T\right)$, where $f^{*}=f / A^{*}$ is the nominal stress, $A^{*}$ is the undeformed cross-sectional area of the sample, and $T$ is the absolute temperature. Typical results for the $\mathrm{Al}$ networks are shown in Figure 2, and the cor-

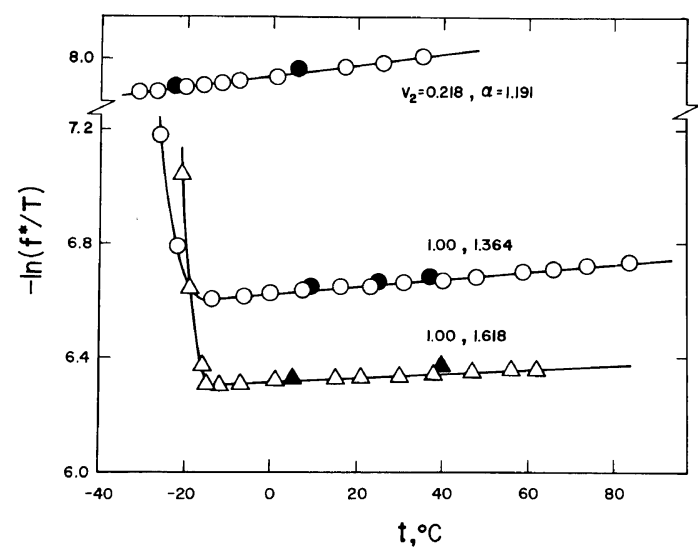

Figure 2. Typical thermoelastic results, at constant length, for A1 networks (of high-cis polybutadiene). The open symbols show the results obtained upon decreasing the temperature, and the filled symbols, the results obtained upon subsequent increase in temperature to check for reversibility. Each curve is labelled with the volume fraction of polymer present in the network, and the elongation at $25^{\circ} \mathrm{C}$. Additional details are given in Table II.

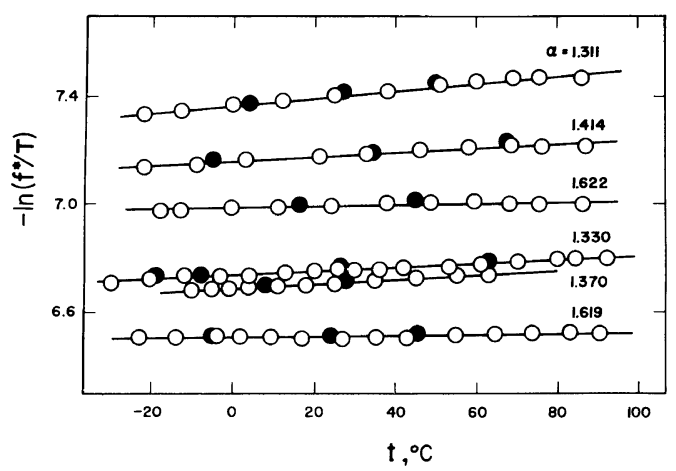

Figure 3. Thermoelastic results for the (unswollen) B1 and B2 networks (of the cis-trans butadiene copolymer). See legend to Figure 2, and the corresponding entries in Table II 
responding results for the $\mathrm{B} 1$ and $\mathrm{B} 2$ networks in Figure 3. Values of the volume fraction $v_{2}$ of polymer in the networks during the measurements, and values of the elongation $\alpha$ used in all of the experiments are given in columns three and four of Table II. The curves obtained are seen to be highly reversible, as is required for the subsequent thermodynamic and molecular analysis. The observed deviations from linearity in the case of the Al networks correspond to marked decreases in the force, and are clearly due to network crystallization. ${ }^{17,43-45}$ Very similar decreases in $f$ have been reported for highly crystallizable networks of natural rubber $^{46}$ as well as high-cis polybutadiene. ${ }^{17,47,48}$ As shown in Figure 2, the anomalous behavior is suppressed in the case of the networks containing diluent, which acts to decrease the amount of crystallinity through decrease in $T_{\mathrm{m}}{ }^{49}$ This thermoelastic method is however apparently not sensitive enough to detect any crystallinity in the $\mathrm{B} 1$ and $\mathrm{B} 2$ networks.

In view of the above analysis, only the linear portions of the thermoelastic curves could be used to obtain values of the fraction $f_{\mathrm{e}} / f$ of the force which is energetic in origin and the temperature coefficient $\mathrm{d} \ln \left\langle r^{2}\right\rangle_{0} / \mathrm{d} T$ of the unperturbed dimensions. ${ }^{7}$ The average values of the (absolute) temperature for these regions are given in column five of Table II. The slopes of these linear portions of the curves were interpreted using the standard equations, ${ }^{50-52}$

$$
\begin{aligned}
f_{\mathrm{e}} / f= & T d \ln \left\langle r^{2}\right\rangle_{0} / \mathrm{d} T \\
& =-T\left[\partial \ln \left(f^{*} / T\right) / \partial T\right]_{\mathrm{p}, \mathrm{L}} \\
& -\beta T /\left(\alpha^{3}-1\right)
\end{aligned}
$$

The values of $f_{\mathrm{e}} / f$ and $10^{3} \mathrm{~d} \ln \left\langle r^{2}\right\rangle_{0} / \mathrm{d} T$ thus ob-

\begin{tabular}{|c|c|c|c|c|c|c|}
\hline \multirow{2}{*}{ Network } & Dose & \multirow{2}{*}{$v_{2}^{a}$} & \multirow{2}{*}{$\alpha^{\mathrm{b}}$} & $\bar{T}$ & \multirow{2}{*}{$f_{\mathrm{e}} / f$} & \multirow{2}{*}{$\frac{10^{3} \mathrm{~d} \ln \left\langle r^{2}\right\rangle_{0} / \mathrm{d} T}{\mathrm{~K}^{-1}}$} \\
\hline & Mrad & & & K & & \\
\hline \multirow[t]{4}{*}{$\mathrm{A} 1$} & 21 & 1.00 & 1.270 & 313.2 & 0.44 & 1.42 \\
\hline & & & 1.364 & 313.2 & 0.26 & 0.84 \\
\hline & & & 1.618 & 313.2 & 0.17 & 0.53 \\
\hline & & & 1.517 & 313.2 & 0.29 & 0.94 \\
\hline \multirow[t]{3}{*}{ B1 } & 12 & 1.00 & 1.311 & 298.2 & 0.23 & 0.77 \\
\hline & & & 1.414 & 298.2 & 0.12 & 0.39 \\
\hline & & & 1.622 & 298.2 & 0.01 & 0.03 \\
\hline \multirow[t]{3}{*}{ B2 } & 21 & 1.00 & 1.330 & 298.2 & 0.06 & 0.21 \\
\hline & & & 1.370 & 298.2 & 0.10 & 0.34 \\
\hline & & & 1.619 & 298.2 & 0.04 & 0.14 \\
\hline $\mathrm{A} 1^{\mathrm{c}}$ & 21 & 0.218 & 1.191 & 298.2 & 0.17 & 0.58 \\
\hline$B 2^{\mathrm{c}}$ & 21 & 0.196 & 1.207 & 283.2 & 0.06 & 0.22 \\
\hline \multirow[t]{5}{*}{$\mathrm{B} 2^{\mathrm{d}}$} & 21 & 0.555 & 1.238 & 283.2 & 0.09 & 0.31 \\
\hline & & 0.443 & 1.231 & 283.2 & 0.28 & 0.98 \\
\hline & & 0.310 & 1.176 & 283.2 & 0.19 & 0.67 \\
\hline & & 0.277 & 1.121 & 283.2 & 0.23 & 0.80 \\
\hline & & 0.184 & 1.205 & 283.2 & 0.03 & 0.08 \\
\hline
\end{tabular}
tained are given in the last two columns of Table II.

Table II. Thermoelastic results

a Volume fraction of polymer in the network during elasticity measurements.

b Elongation at $25^{\circ} \mathrm{C}$.

c Swollen with 1,3,5-triethylbenzene.

d Swollen with decalin. 
For the high-cis polymer, the data yield the average result $10^{3} \mathrm{~d} \ln \left\langle r^{2}\right\rangle_{0} / \mathrm{d} T=0.86( \pm 0.32)$, in satisfactory agreement with values reported in some other experimental studies, ${ }^{53,54}$ and with the results ${ }^{4,6}$ of rotational isomeric state calculations. The positive values of $f_{\mathrm{e}} / f$ are primarily due to the fact that stretching a high-cis polybutadiene network requires transitions from relatively compact $\pm 60^{\circ}$, $\pm 60^{\circ}$ conformational states about $\mathrm{CH}-\mathrm{C}_{2} \mathrm{H}_{2}-\mathrm{CH}$ bond pairs to more extended $\pm 60^{\circ}, 0^{\circ}$ and $0^{\circ}, \pm 60^{\circ}$ states of higher energy. ${ }^{4}$ Similarly, $\left\langle r^{2}\right\rangle_{0}$ increases with increase in temperature primarily because the absorption of the thermal energy requires an increase in the number of higher-energy conformations, and these are the more extended states. ${ }^{4}$ The average values of $f_{\mathrm{e}} / f$ and $10^{3} \mathrm{~d} \ln \left\langle r^{2}\right\rangle_{0} / \mathrm{d} T$ for the cis-trans copolymer were found to be 0.12 $( \pm 0.09)$ and $0.39( \pm 0.32) \mathrm{K}^{-1}$, respectively. These values are thus significantly smaller than those obtained for the high-cis polymer, an observation which is also in agreement with rotational isomeric state calculations. ${ }^{6}$

The birefringence results obtained on some of the unswollen Al newtworks are presented in Figure 4, and all of the results on the unswollen B1 and B2 networks in Figure 5. These results generally show the same high degrees of reproducibility found in the thermoelastic results. As expected, ${ }^{21-23} \Delta n$ increases markedly when crystallization occurs, and then frequently exhibits considerable hysteresis. The changes in $\Delta n$ are generally considerably larger than those observed for the force, and thus, $\Delta n$ is found

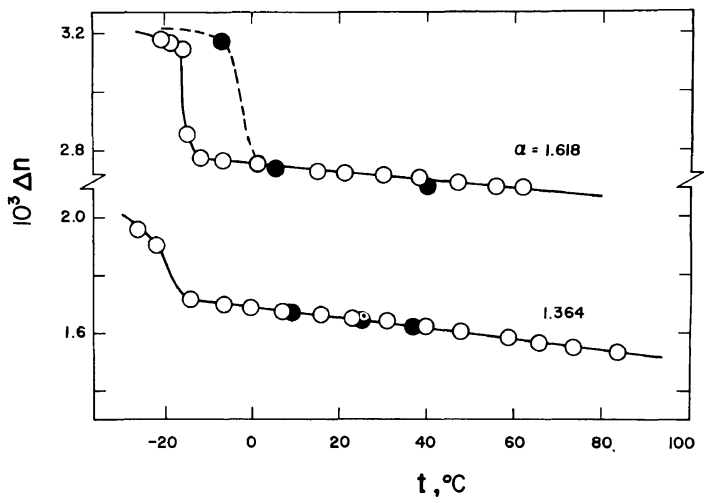

Figure 4. Strain birefringence shown as a function of temperature for some (unswollen) A1 networks, including reversibility checks. The increase in $\Delta n$ and the hysteresis exhibited at low temperatures are characteristics of network crystallization. ${ }^{21,23}$ to be a much more sensitive measure of network crystallization. Some crystallization is now clearly in evidence in the case of the cis-trans polymer and, on the basis of Figure 1, may be attributed to trans sequences. It is interesting to note that this occurs approximately $45^{\circ}$ above its occurrence in the highcis polymer, which is consistent with crystallization of trans rather than cis sequences, as expected. In any case, it is important to note that the cis-trans copolymer exhibits some departures from linearity at temperatures as high at $40^{\circ} \mathrm{C}$. The viscoelastic losses observed in this temperature range are quite ambiguous, but are suggestive of network crystallization.

These results were also used to calculate the values of the optical-configuration parameter defined by ${ }^{36,55}$

$$
\Delta a=(45 k T / 2 \pi)\left[n /\left(n^{2}+2\right)^{2}\right][\Delta n /(f / A)]
$$

where $k$ is the Boltzmann constant, and $A$ is the cross-sectional area of the streiched sample (and $f / A$ is thus the "true" stress). Representative values for both the B networks in the unswollen state are given in Figure 6, and are seen to be independent of both the degree of cross-linking and elongation.

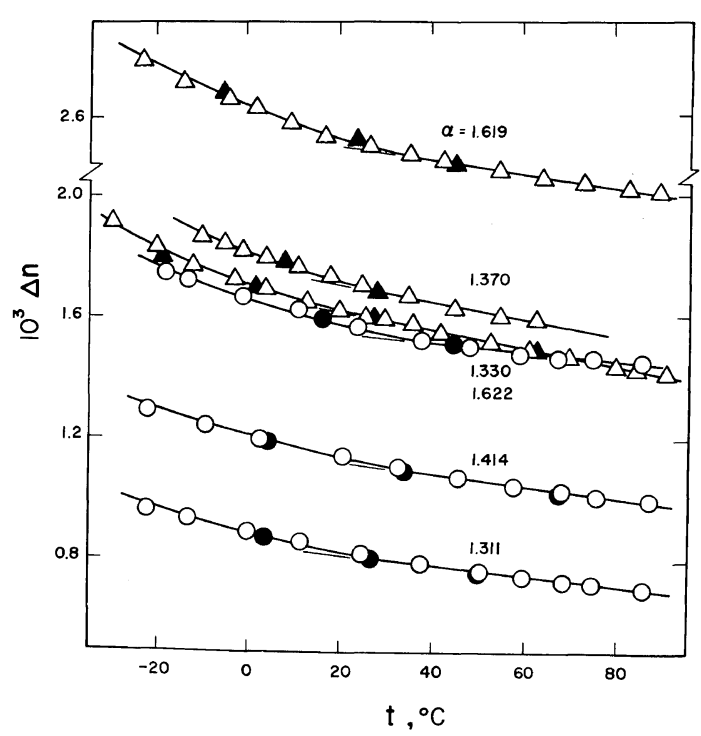

Figure 5. Strain birefringence shown as a function of temperature for the (unswollen) B1 $(O)$ and B2 $(\triangle)$ networks, including reversibility checks for both networks. The short extensions of the linear portions of the curves help locate the values of the temperature at which deviations from linearity first become discernible. 


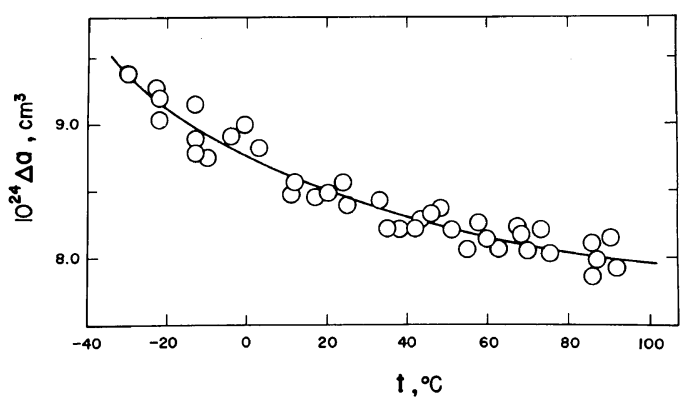

Figure 6. The optical-configuration parameter, for representative elongations of the (unswollen) B1 and B2 networks.

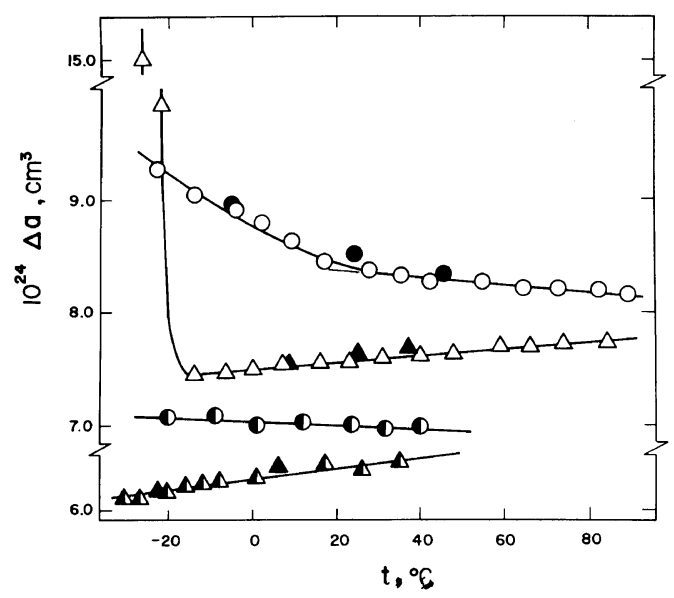

Figure 7. The optical-configuration parameter for network $\mathrm{Al}$ in the unswollen state $(\triangle)$ and swollen with 1,3,5-triethylbenzene (volume fraction of polymer $\left.v_{2}=0.218\right)(\triangle)$, and network B2 in the unswollen state (O) and swollen with the same diluent $\left(v_{2}=0.196\right)$ (O). The corresponding values of the elongation are given in Table III.

Typical values of $\Delta a$ for the A1 and $\mathrm{B} 2$ networks in the unswollen and swollen states are shown in Figure 7. Both types of network give clear evidence for crystallization in the unswollen state; it is not as pronounced in the case of the cis-trans copolymer, which is consistent with a lower degree of crystallinity. This quantity is particularly sensitive to crystallization, which increases $\Delta n$ and decreases $f$, since these two quantities appear in the numerator and denominator, respectively in the defining relationship for $\Delta a$. The presence of diluent is seen to suppress the crystallinity in both cases, as expected.

All of the above results indicate that significant

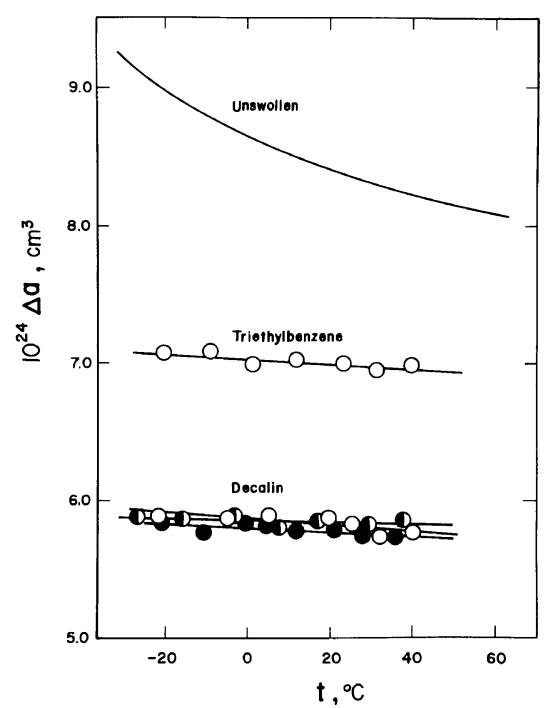

Figure 8. More detailed comparisons between the optical-configuration parameter for the swollen and unswollen B2 networks. In the case of the network swollen with 1,3,5-triethylbenzene, the value of the volume fraction $v_{2}$ of polymer in the network was 0.196 ; for the decalin-swollen networks the three representative curves correspond to $v_{2}=0.555(\bigcirc), 0.310(\mathbf{O})$, and $0.184(\bigcirc)$. Values of the elongation for all of the curves are given in Table III.

amounts of crystallization are present in the cistrans copolymers, at low elongations, and can persist to relatively high temperatures. If present in small crystallites, in relatively small amounts, this crystallization would probably not be detected by less sensitive techniques such as $\mathrm{X}$-ray diffraction or differential scanning calorimetry. In addition, the thermodynamic analysis summarized in Figure 1 indicates that such crystallization is very likely to be present even in the unstretched networks. Similar comments have been found to apply ${ }^{23}$ to ethylenepropylene networks. ${ }^{26}$ These results therefore strongly support Flory's contention ${ }^{14}$ that the unusually high values of the modulus reported ${ }^{13,26}$ for some networks should be attributed to reinforcing effects from network crystallization rather than to highly speculative contributions from inter-chain entaglements. ${ }^{56-63}$ It would thus seem to be extremely difficult to use cis-trans butadiene ${ }^{13}$ or ethylene-propylene ${ }^{26}$ elastomers for evaluating the molecular theories of rubberlike elasticity, at least when the networks are in the unswollen state. Far 
Table III. Temperature dependence of the strain birefringence and optical-configuration parameter ${ }^{\mathrm{a}}$

\begin{tabular}{|c|c|c|c|c|}
\hline \multirow{2}{*}{ Network } & \multirow{2}{*}{$v_{2}$} & \multirow{2}{*}{$\alpha$} & \multirow{2}{*}{$\frac{-10^{6} \mathrm{~d} \Delta n / \mathrm{d} T}{\mathrm{~K}^{-1}}$} & \multirow{2}{*}{$\frac{-10^{26} \mathrm{~d} \Delta a / \mathrm{d} T}{\mathrm{~cm}^{3} \mathrm{~K}^{-1}}$} \\
\hline & & & & \\
\hline \multirow[t]{4}{*}{$\mathrm{A} 1$} & 1.00 & 1.270 & 1.66 & -0.31 \\
\hline & & 1.364 & 1.87 & -0.31 \\
\hline & & 1.618 & 1.43 & -0.37 \\
\hline & & 1.517 & 1.59 & -0.35 \\
\hline \multirow[t]{3}{*}{ B1 } & 1.00 & 1.311 & 1.69 & 0.74 \\
\hline & & 1.414 & 1.79 & 0.90 \\
\hline & & 1.622 & 1.47 & 0.71 \\
\hline \multirow[t]{3}{*}{ B2 } & 1.00 & 1.330 & 2.96 & 0.71 \\
\hline & & 1.370 & 2.74 & 0.57 \\
\hline & & 1.619 & 2.41 & 0.29 \\
\hline $\mathrm{Al}$ & 0.218 & 1.191 & 0.51 & -0.49 \\
\hline $\mathrm{B} 2$ & 0.196 & 1.207 & 0.53 & 0.19 \\
\hline \multirow[t]{5}{*}{ B2 } & 0.555 & 1.238 & 0.89 & 0.24 \\
\hline & 0.443 & 1.231 & 1.21 & 0.22 \\
\hline & 0.310 & 1.176 & 0.60 & 0.07 \\
\hline & 0.277 & 1.121 & 0.69 & 0.01 \\
\hline & 0.184 & 1.205 & 0.38 & 0.14 \\
\hline
\end{tabular}

a See footnotes to Table II.

better in this regard are poly(dimethylsiloxane) networks, ${ }^{62-64}$ which have extremely low melting points, ${ }^{11}$ or poly(ethyl acrylate) networks, ${ }^{14}$ which have never been reported to crystallize at all. ${ }^{11}$

The effect of swelling on $\Delta a$ for the B2 networks is explored in more detail in Figure 8. The lowest values of $\Delta a$ are considered the most reliable. ${ }^{32-37}$ and thus the ones to be used for comparisons with the results of rotational isomeric state calculations. Therefore, for example, the preferred value of $\Delta a$ for the cis-trans copolymer at $50^{\circ} \mathrm{C}$ is $5.78 \times 10^{-24}$ $\mathrm{cm}^{3}$. Frequently the temperature dependence of a configuration-dependent property is of greater interest than the property itself. ${ }^{7}$ For this reason, the values of the temperature coefficients of $\Delta n$ and $\Delta a$ are separately presented in Table III.

A final quantity of interest is the stress-optical coefficient, which is defined by $21,22,36,42,55$

$$
C=\Delta n /(f / A)
$$

and is thus simply the slope of a plot of the birefringence against the true stress. Typical results for the A1 networks are presented in Figure 9. The complete set of values of $C$ thus obtained are given in Table IV, and representative values are shown as a function of temperature in Figure 10. They are seen to be independent of degree of cross-linking, as expected. ${ }^{21,42}$ It is interesting to note, however, that the dependence of $C$ on temperature for the B networks is non-linear over essentially the entire range investigated. This is presumably due to the fact that the stress-optical coefficient (like the optical-configuration parameter) is extremely sensitive to crystallization because of simultaneous increases in the numerator and decreases in the denominator in the defining relationship $C=$ $\Delta n /(f / A)$.

The present results are compared with other experimental results in the literature ${ }^{39,40}$ in Table V. The agreement is seen to be very good. The most reliable (lowest) values of $10^{24} \Delta a$ for the high-cis and cis-trans copolymer at $50^{\circ} \mathrm{C}$ are 6.52 and 5.78 


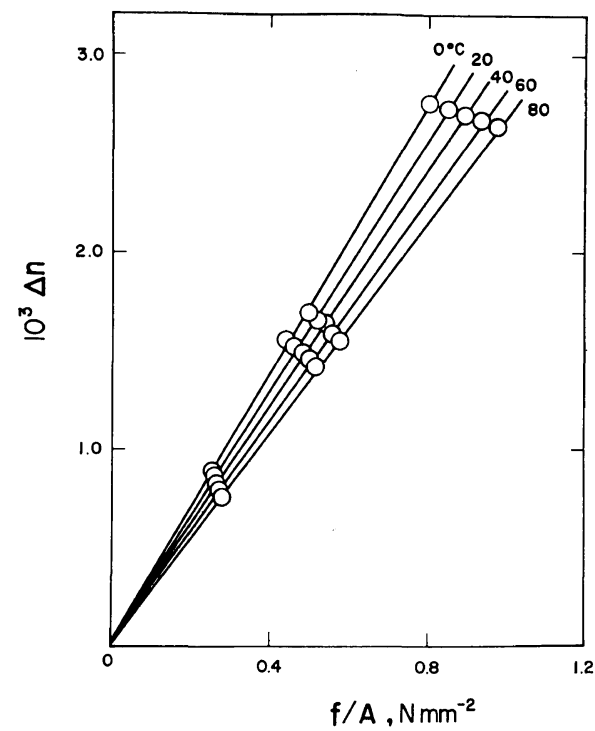

Figure 9. Typical results (obtained on network A1) showing the dependence of the birefringence on the true stress, from experiments carried out by varying the temperature at constant length. The slope of each curve is the stress-optical coefficient $C$.

Table IV. Values of the stress-optical coefficient $C^{\mathrm{a}}$ at various temperatures ${ }^{\mathrm{b}}$

\begin{tabular}{lccccc}
\hline Network & 0 & 20 & 40 & 60 & 80 \\
\hline A1 & 3.39 & 3.16 & 2.97 & 2.82 & 2.67 \\
B1 & 4.22 & 3.73 & 3.33 & 3.07 & 2.89 \\
B2 & 4.06 & 3.70 & 3.34 & 3.11 & 2.92 \\
\hline
\end{tabular}

${ }^{a}$ In $10^{-3}\left(\mathrm{~N} / \mathrm{mm}^{2}\right)^{-1}$.

${ }^{b}$ In ${ }^{\circ} \mathrm{C}$.

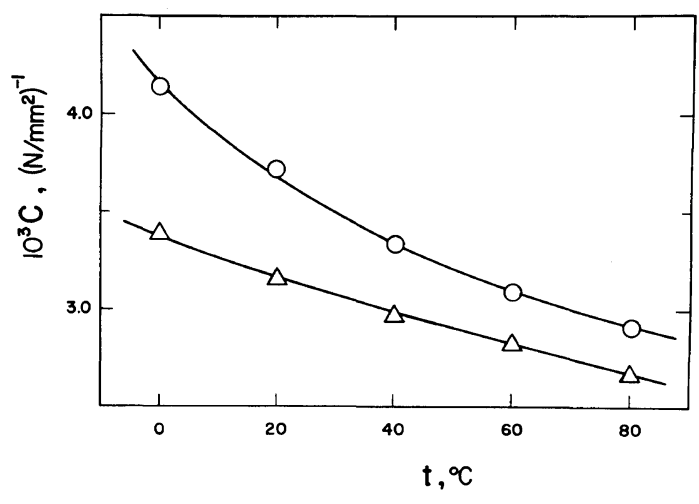

Figure 10. The temperature dependence of the stressoptical coefficients for the $\mathrm{A} 1(\triangle)$ and (the averaged) B1 and $\mathrm{B} 2(\bigcirc)$ networks.

$\mathrm{cm}^{3}$, respectively. They are in good agreement with the (minimum) values of 5.35 and 5.68, respectively, reported by Stein and coworkers ${ }^{21}$ for some polybutadiene networks having similar compositions, and swollen in a variety of solvents. They are also in satisfactory agreement with the corresponding values calculated from the rotational isomeric state theory, specifically 5.88 and 5.83, respectively. ${ }^{6}$ The experimental values of the temperature coefficients of $\Delta a$ will require separate interpretation in a later investigation.

A few final experiments were carried out by varying the network length at a constant tmperature of $25^{\circ} \mathrm{C}$. These results were interpreted in terms of the modulus or reduced stress $\left[f^{*}\right]=f^{*} /\left(\alpha-\alpha^{-2}\right)$, as is illustrated in Figure 11. In the case of the highcis network, the abrupt decrease and subsequent increase in $\left[f^{*}\right]$ are due to strain-induced crystallization. ${ }^{17,44,45,47,48,65}$ Of greater interest, however, are the values of the low deformation modulus

Table V. Comparisons with results of other birefringence experiments

\begin{tabular}{|c|c|c|c|c|c|}
\hline $\begin{array}{c}\text { PBD } \\
\text { Composition }\end{array}$ & Property & $t,{ }^{\circ} \mathrm{C}$ & Nagai $^{a}$ & Treloar $^{b}$ & $\begin{array}{l}\text { Present } \\
\text { study }\end{array}$ \\
\hline \multirow[t]{3}{*}{$96-98.5 \%$ cis } & $C^{\mathrm{c}}$ & 20 & - & 3.30 & 3.16 \\
\hline & $\Delta a^{\mathrm{d}}$ & 20 & $7.51,5.63^{\mathrm{e}}$ & 7.77 & $7.71,6.36^{\mathrm{e}}$ \\
\hline & $\Delta a^{\mathrm{d}}$ & 50 & 7.75 & - & $7.80,6.52^{\mathrm{e}}$ \\
\hline \multirow[t]{3}{*}{$43-45 \%$ cis } & $C^{\mathrm{c}}$ & 20 & - & 3.69 & 3.72 \\
\hline & $\Delta a^{\mathrm{d}}$ & 20 & - & 8.74 & $8.48,5.82^{\mathrm{e}}$ \\
\hline & $\Delta a^{\mathrm{d}}$ & 50 & - & - & $8.20,5.78^{\mathrm{e}}$ \\
\hline
\end{tabular}

${ }^{a}$ Reference 39. ${ }^{b}$ Reference $40 .{ }^{c}$ In $10^{-3}\left(\mathrm{~N} / \mathrm{mm}^{2}\right)^{-1} .{ }^{\mathrm{d}}$ In $10^{-24} \mathrm{~cm}^{3}$. e Swollen networks. 


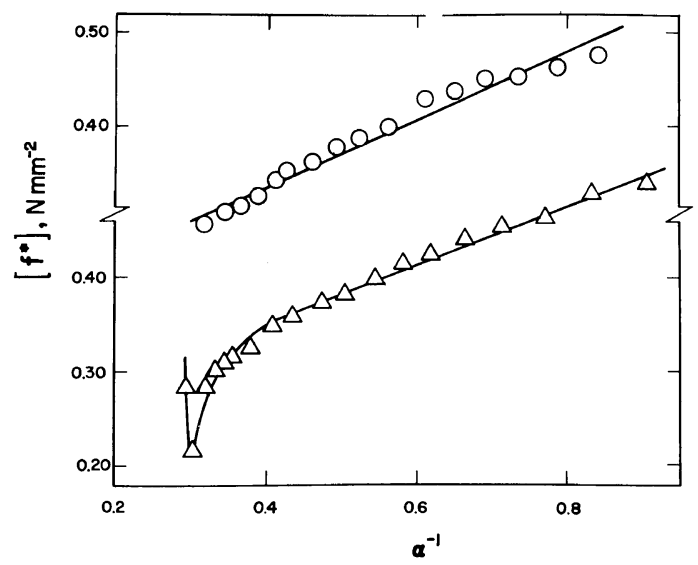

Figure 11. Stress-strain isotherms for the $A l(\triangle)$ and $\mathrm{B} 2(\mathrm{O})$ networks at $25^{\circ} \mathrm{C}$. Abrupt changes in modulus in the case of network $\mathrm{A} 1$ are due to strain-induced crystallization. ${ }^{17,47,48,65}$

$2 C_{1}+2 C_{2}$ of the cis-trans copolymer. Swelling these networks in decalin to very small values of $v_{2}$ was found to decrease the modulus from approximately 0.6 to $0.1 \mathrm{~N} \mathrm{~mm}^{-2}$. Although difficult to interpret quantitatively, this decrease is much larger than would be expected, ${ }^{24,25,59}$ and is consistent with the presence of crystallization and crystallite reinforcement in the case of the unswollen networks.

Acknowledgements. It is a pleasure to acknowledge the financial support provided by the National Science Foundation through Grant DMR 79-18903 (Polymers Program, Division of Materials Research), and the postdoctoral fellowship awarded M.A.L. through the Joint Spain-United States Treaty for Scientific and Technological Cooperation. We also wish to thank Professor S. Cesca of the Snamprogetti Laboratories and Dr. G. Kraus of the Phillips Petroleum Company for providing the samples used in this study, and to acknowledge some very helpful discussions with Professor P. J. Flory of Stanford University.

\section{REFERENCES}

1. R. S. Hanmer and H. E. Railsback, in "Rubber Technology," 2nd ed, M. Morton, Ed., Van Nostrand Reinhold, New York, 1973, Chapter 8.

2. R. W. Lenz, "Organic Chemistry of Synthetic High Polymers," Interscience, New York, 1967.

3. D. H. Richards, Chem. Soc. Rev., 6, 235 (1977).

4. J. E. Mark, J. Am. Chem. Soc., 88, 4354 (1966).
5. J. E. Mark, J. Am. Chem. Soc., 89, 6829 (1967).

6. Y. Abe and P. J. Flory, Macromolecules, 4, 219 (1971).

7. P. J. Flory, "Statistical Mechanics of Chain Molecules," Interscience, New York, 1969.

8. G. Natta and G. Moraglio, Makromol. Chemie, 66, 218 (1963).

9. L. Mandelkern, "Crystallization of Polymers," McGraw-Hill, New York, 1964; B. Wunderlich, “Macromolecular Physics, Vol. 1," Academic Press, New York, 1973.

10. "Polymer Handbook," 2nd ed, by J. Brandrup and E. H. Immergut, Ed., Wiley-Interscience, New York, 1975.

11. Y. Akana and R. S. Stein, J. Polym. Sci., Polym. Phys. Ed., 13, 2195 (1975).

12. P. J. Flory, Trans. Faraday. Soc., 51, 848 (1955).

13. L. M. Dossin and W. W. Graessley, Macromolecules, 12, 123 (1979).

14. B. Erman, W. Wagner, and P. J. Flory, Macromolecules, 13, 1554 (1980).

15. It seems relevant in this regard that less protracted stress-strain experiments on very similar cis-trans polybutadiene networks [G. Kraus and G. A. Moczvgemba, J. Polym. Sci., A, 2, 277 (1964)] give values of the elongation modulus which are much lower than those reported in ref 13. They are in fact inconsistent with large contributions from interchain entanglements.

16. P. J. Flory, J. Am. Chem. Soc., 78, 5222 (1956).

17. J. E. Mark, Polym. Eng. Sci., 19, 254 (1979); ibid., 19, 409 (1979).

18. T. J. Hammack and R. D. Andrews, J. Appl. Phys., 38, 5182 (1967).

19. N. J. Mills, "Polymer Science," A. D. Jenkins, Ed., North-Holland, 1972, Chapter 7.

20. J. Durisin and H. L. Williams, J. Appl. Polym. Sci., 17, 709 (1973).

21. M. Fukuda, G. L. Wilkes, and R. S. Stein, J. Polym. Sci., A-2, 9, 1417 (1971); R. S. Stein, Rubber Chem. Technol., 49, 458 (1976).

22. R. S. Stein and S. D. Hong, J. Macromol. Sci., Phys., B12, 125 (1976).

23. M. A. Llorente and J. E. Mark, J. Polym. Sci., Polym. Phys. Ed., 19, 000 (1981).

24. P. J. Flory, Proc. R. Soc. London, Ser. A, 351, 351 (1976).

25. P. J. Flory, Polymer, 20, 1317 (1979).

26. D. S. Pearson and W. W. Graessley, Macromolecules, 13, 1001 (1980).

27. M. Bruzzone, A. Mazzei, and G. Giuliani, Rubber Chem. Technol., 47, 1175 (1974).

28. G. Lugli, A. Mazzei, and S. Poggio, Makromol. Chemie, 175, 2021 (1974).

29. S. Cesca, private communications.

30. G. Kraus, private communications.

31. "Handbook of Chemistry and Physics," 58th ed, 
CRC Press, Cleveland, 1977.

32. K. Nagai, J. Chem. Phys., 47, 4690 (1967).

33. A. N. Gent, Macromolecules, 2, 262 (1969).

34. T. Ishikawa and K. Nagai, Polym. J., 1, 116 (1970).

35. A. N. Gent and T. H. Kuan, J. Polym. Sci., A-2, 9, 927 (1971).

36. M. H. Liberman, Y. Abe, and P. J. Flory, Macromolecules, 5, 550 (1972).

37. T. Ishikawa, Polym. J., 5, 227 (1973).

38. M. A. Sharaf, Ph.D. Thesis in Chemistry, The University of Michigan, 1979.

39. T. Ishikawa and K. Nagai, J. Polym. Sci., A-2, 7, 1123 (1969).

40. R. J. Morgan and L. R. G. Treloar, J. Polym. Sci., $A-2,10,51$ (1972).

41. R. H. Valentine, J. D. Ferry, T. Homma, and K. Ninomiya, J. Polym. Sci., A-2, 6, 479 (1968).

42. L. R. G. Treloar, "The Physics of Rubber Elasticity," 3rd Ed., Clarendon Press, Oxford, 1975.

43. A. De Chirico, P. C. Lanzani, E. Raggi, and M. Bruzzone, Makromol. Chem., 175, 2029 (1974).

44. G. P. Giuliani, E. Sorta, and M. Bruzzone, Angew. Makromol. Chem., 50, 87 (1976).

45. L. Gargani, G. P. Giuliani, F. Mistrali, and M. Bruzzone, Angew. Makromol. Chem., 50, 101 (1976).

46. K. J. Smith, Jr., A. Greene, and A. Ciferri, Kolloid Z. Z. Polym., 194, 49 (1964).

47. T.-K. Su and J. E. Mark, Macromolecules, 10, 120 (1977).

48. D. S. Chiu, T.-K. Su, and J. E. Mark, Macromolecules, 10, 1110 (1977).

49. P. J. Flory, "Principles of Polymer Chemistry," Cornell University Press, Ithaca, N.Y., 1953.

50. P. J. Flory, A. Ciferri, and C. A. J. Hoeve, J. Polym. Sci., 45, 235 (1960).

51. A. Ciferri, C. A. J. Hoeve, and P. J. Flory, J. Am. Chem. Soc., 83, 1015 (1961).

52. J. E. Mark, J. Polym. Sci., Macromol. Rev., 11, 135 (1976).

53. J. E. Mark, Rubber Chem. Technol., 46, 593 (1973).
54. R. H. Becker, C. U. Yu, and J. E. Mark, Polym. J., 7, 234 (1975).

55. M. H. Liberman, L. C. DeBolt, and P. J. Flory, $J$. Polym. Sci., Polym. Phys. Ed., 12, 187 (1974).

56. There are also serious difficulties in the DossinGraessley assumption (ref 13) that the decreased values of the low deformation modulus $2 C_{1}+2 C_{2}$ observed for a polybutadiene network cross-linked in solution and studied in the swollen state are due to a decrease in the number of inter-chain entanglements. This assumption neglects the results of numerous studies which have shown that (i) a network prepared in solution has a greatly decreased value of the constant $2 C_{2}$ (ref 57-59), (ii) swollen networks have diminished values of $2 C_{2}$ (ref 42, 58, and 59), (iii) reinforcement from network crystallization would be diminished by swelling (ref 17 and 48), and (iv) cross-linking in solution can give a considerable number of wasted intra-molecular cross-links or chain "loops" (ref 60 and 61). It is also contradicted by the results of several studies of poly(dimethylsiloxane) networks prepared in solution (ref 62 and 63).

57. J. E. Mark, J. Am. Chem. Soc., 92, 7252 (1970).

58. C. Price, G. Allen, F. de Candia, M. C. Kirkham, and A. Subramaniam, Polymer, 11, 486 (1970).

59. J. E. Mark, Rubber Chem. Technol., 48, 495 (1975), and pertinent references cited therein.

60. A. E. Tonelli and E. Helfand, Macromolecules, 7, 59 (1974); ibid., 8, 248 (1975).

61. A. E. Tonelli, Polymer, 15, 194 (1974).

62. M. A. Llorente and J. E. Mark, J. Chem. Phys., 71, 682 (1979).

63. J. E. Mark and M. A. Llorente, J. Am. Chem. Soc., 102, 632 (1980).

64. A. L. Andrady, M. A. Llorente, and J. E. Mark, J. Chem. Phys., 72, 2282 (1980).

65. M. Cesari, L. Gargani, G. P. Giuliani, G. Perego, and A. Zazzeta, J. Polym. Sci., B, 14, 107 (1976). 